\section{Investigating the Impact of Knee Prosthesis in Patients' Body on Radiation Dose Distribution: A Monte Carlo Approach}

\author{
Bayatiani M. R. ${ }^{1}$, Seif F. ${ }^{1 *}$, Hamidi S. ${ }^{2}$, Bagheri S. ${ }^{3}$
}

\begin{abstract}
Background: Metal prostheses in patients affect the radiotherapy dose distribution. Metal prostheses with high density and atomic number cause major changes in scattering and attenuation of radiation. The present study aims to assess the impact of metal knee prosthesis with various dimensions and materials on radiotherapy dose distribution.
\end{abstract}

Material and Methods: In this research, the Varian Linac and water phantom were simulated using the MCNPX code. Dose distribution of photon beam in a water phantom, with and without the presence of knee prostheses made of cobalt-chromium-molybdenum alloy, steel, titanium, and titanium alloy used in men and women was investigated using the Monte Carlo simulation.

Results: The prosthesis led to an increase in dose in comparison with cases that there was used no prosthesis. According to values of the depth dose percentage, the maximum dose increase was found to be $6.8 \%, 6.1 \%, 4 \%$, and $4.29 \%$, and dose reduction $41.18 \%, 40.66 \%, 37.76 \%$, and $37.51 \%$ for prosthetics with men's knee dimensions made of cobalt-chromium-molybdenum alloy, steel, titanium alloy, and titanium, respectively. Above all, does increasing to $6.4 \%, 5.9 \%, 3.8 \%$, and $3.94 \%$ and doses reducing to $40.87 \%, 40.36 \%, 36.94 \%$, and 36.69 were observed in prosthetics for women. The highest amount of dose reduction for men's prostheses made of mentioned materials was found to be $48.75 \%, 47.7 \%, 45 \%$, and $45.8 \%$, respectively. In addition, it was $46.36 \%, 45.8 \%, 43.8 \%$, and $43.95 \%$ for women's prostheses, respectively.

Conclusion: Material will have a significant impact if a part of the knee bone places behind the prosthesis. According to the obtained values, it is recommended to utilize prostheses made of titanium and titanium alloys for knee arthroplasty. The prosthesis can either increase or decrease dose in tumor or lead to increase dose at organs at risk.

Citation: Bayatiani M. R, Seif F, Hamidi S, Bagheri S. Investigating the Impact of Knee Prosthesis in Patients' Body on Radiation Dose Distribution: A Monte Carlo Approach. J Biomed Phys Eng. 2019;9(3):345-354. https://doi.org/10.31661/jbpe.v0i0.1047.

\section{Keywords}

Dose Distribution, Knee Prosthesis, Monte Carlo Simulation, Treatment Planning

\section{Introduction}

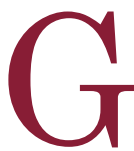
enerally, owing to the expansion of oxidant agents in modern life, an increasing trend has been seen in the number of cancer patients, some of which have metal prostheses. According to a report from the Task Group (TG_63), 1\% to 4\% of cancer patients have metal prostheses which might influence the amount of dosage received in the tumoral area and also healthy tissue near the tumor [1]. Studies
${ }^{1}$ Ph.D of Medical Phys-

ics. Assistant professor,

Department of Medical

Physics and Radio-

therapy, Arak university

of Medical Sciences and

Khansari hospital, Arak,

Iran

${ }^{2}$ Ph.D of Physics. Associ-

ate professor, Depart-

ment of Physics, Arak

University, Arak, Iran

${ }^{3}$ Ms.c of Physics, Depart-

ment of Physics, Arak

University, Arak, Iran

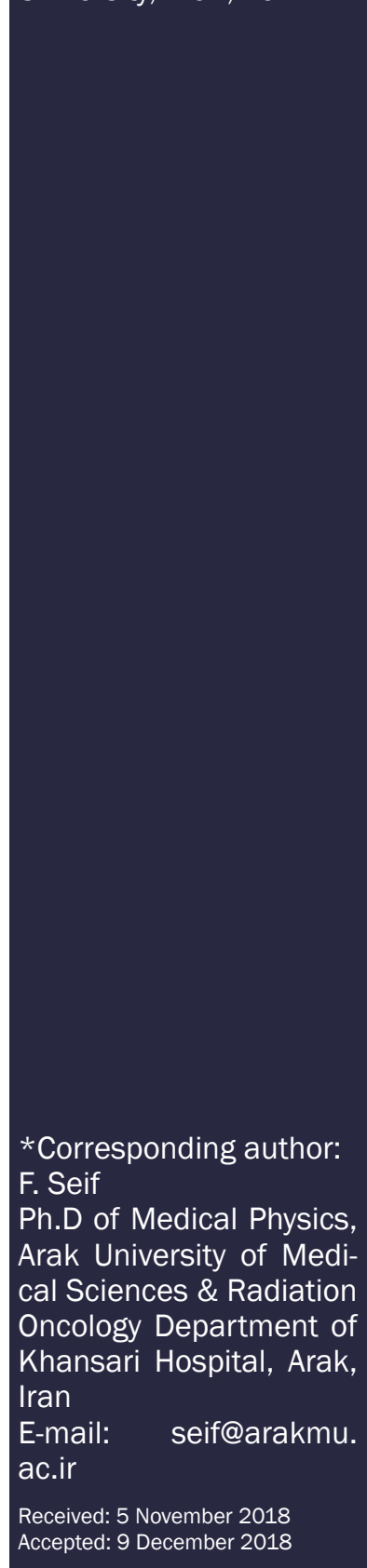


have shown that metal prostheses, with high atomic number and density in medical fields, impacts the dose distribution as heterogeneity [2-4]. Given the fact that the atomic numbers of metal prostheses used in different body parts such as dip joint, knee, arm are much higher than the tissues of the body; therefore, they can have a significant impact on radiotherapy dose distribution [5-9]. Various metals are used in the production of metal prostheses, including cobalt-chromium-molybdenum alloy, stainless steel, titanium alloy, and titanium $[10,11]$.

In radiotherapy, determining absorbed dose precisely and being adapted with the prescribed dose are important. Moreover, if there are any obstacles such as metal prostheses in beam path, dose will either increase or decrease due to changes in the absorption of primary radiation or the distribution of scattered photons $[12,13]$. Megavoltage photon is used in radiotherapy; Compton scattering is a predominant phenomenon while it and beam attenuation are determined by electron density [14]. One of the methods used to investigate dose distribution in radiotherapy is Monte Carlo simulation. The Monte Carlo approach is a high accuracy simulation technique to model physical processes involved in radiotherapy with any geometry [15]. In most of the studies conducted, hip prostheses have been investigated $[1,5,6]$. However, the present study aims to assess the impact of metal knee prosthesis with various dimensions and materials on dose distribution by the Monte Carlo simulation method.

\section{Material and Methods}

In this research, $2100 C / D$ Varian Linear Accelerator, including source, target, primary collimator, vacuum window, ionization chamber, mirrors and secondary collimators, was simulated using the simulated MCNPX Monte Carlo code [16] (Figure 1).

The cut-off energies for electron and photon were assumed to be $0.511 \mathrm{Mev}$ and $0.01 \mathrm{Mev}$

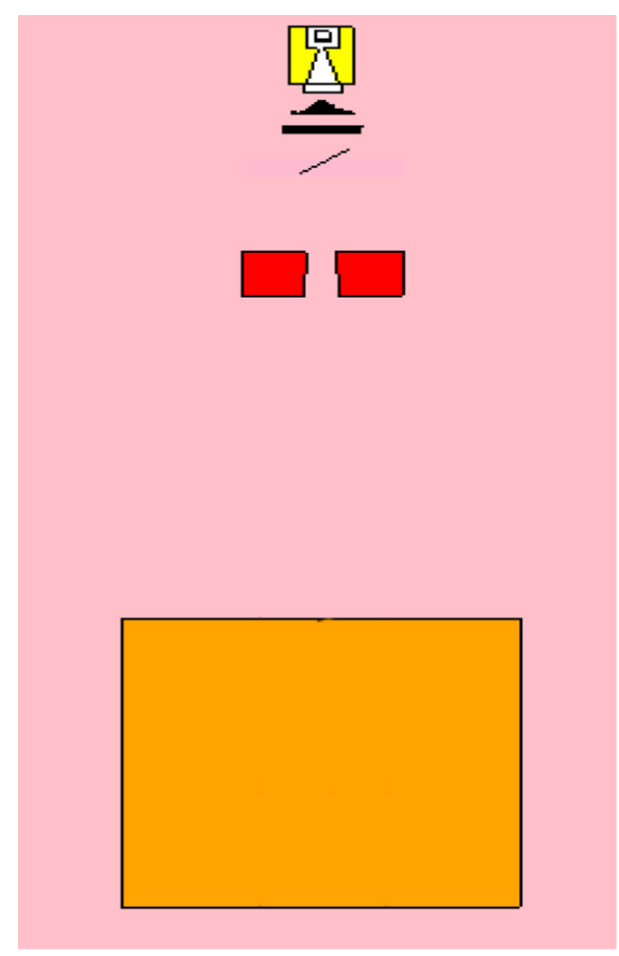

Figure 1: schematic components of Varian 2100 C/D Linac simulation.

respectively. In order to validate the simulation, (PDD) and profile curves were calculated using the Monte Carlo method at $5 \mathrm{~cm}$ depth, $S S D=100 \mathrm{~cm}$ for a field with $10^{\times} 10 \mathrm{~cm}^{2}$ dimensions, in a $50^{\times} 50^{\times} 50 \mathrm{~cm}^{3}$ water phantom, and the obtained results were compared with the results of practical dosimetry (Figure 2).

A cylinder with $0.5 \mathrm{~cm}$ radius and $30 \mathrm{~cm}$ height was considered to simulate PDDs on the central axis of the beam and horizontally at the reference depth of $5 \mathrm{~cm}$ inside the phantom. The cylinders related to PDD and profile calculations were divided into 80 and 36 cells, respectively. The program was run for $180^{\times} 10^{6}$ particles and dosage values were calculated using $*_{f 8}$ in each cell. A cc13 ionization chamber with an inner radius of $0.3 \mathrm{~cm}$ and sensitive volume of $0.13 \mathrm{~cm}^{3}$ manufactured by Scanditronix- wellhöfer (calibrated by SSDL center) and the Omini pro Software were utilized to conduct dosimetry.

After checking the validity of conducted 


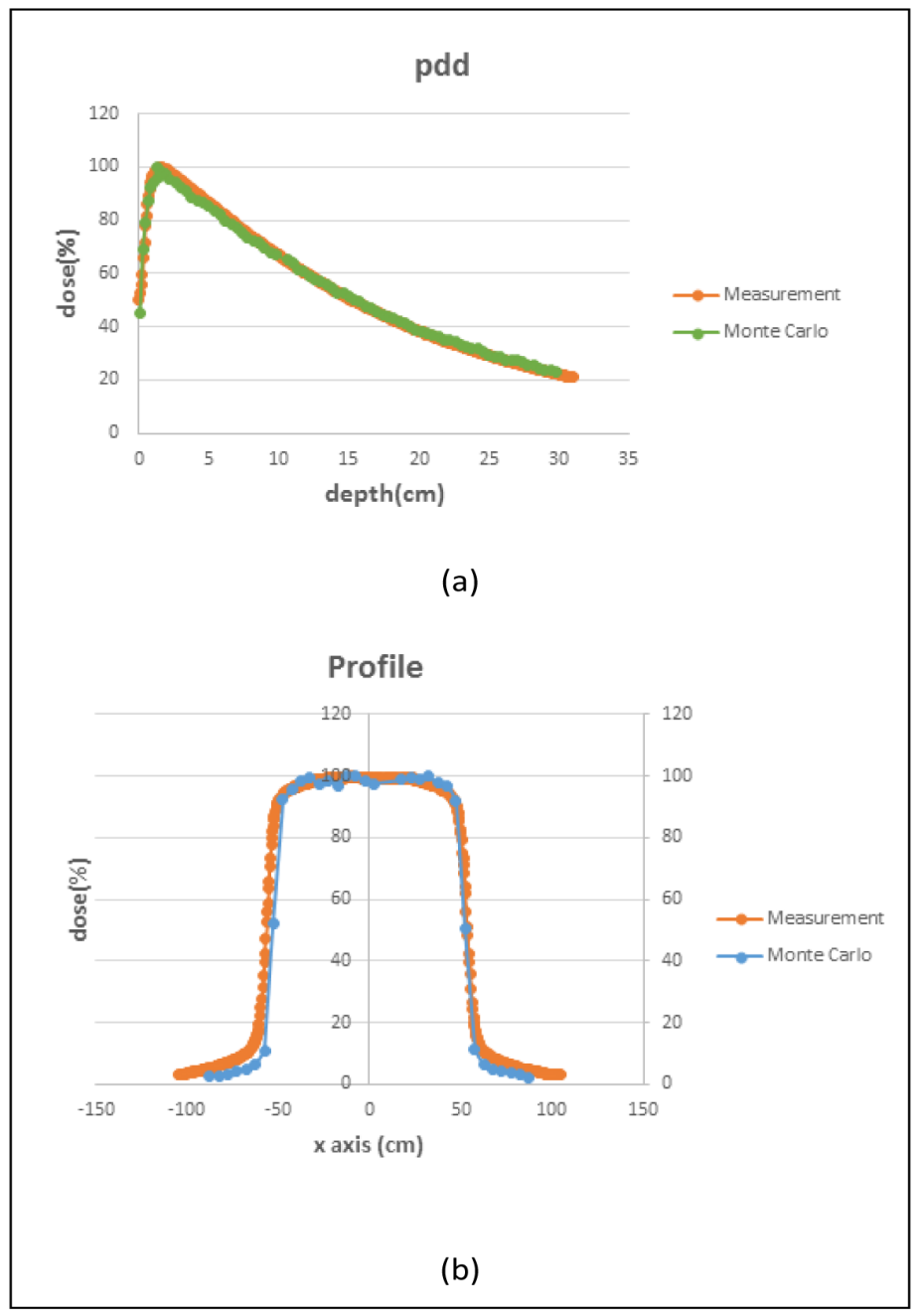

Figure 2: (a) PDDs (b) profiles calculated by MC simulation and dosimetry measurement (6MV, $\left.10 \times 10 \mathrm{~cm}^{2}\right)$.

simulation, knee prostheses were simulated relatively accurate with approximate dimensions of $8^{\times} 6.1^{\times} 6.2 \mathrm{~cm}^{3}$ for men and $7^{\times} 5.5^{\times}$ $5.4 \mathrm{~cm}^{3}$ for women made of cobalt-chromiummolybdenum alloy, stainless steel, titanium alloy, and titanium, with densities of $8.2 \mathrm{~g} / \mathrm{cm}^{3}$, $6.45 \mathrm{~g} / \mathrm{cm}^{3}, 4.48 \mathrm{~g} / \mathrm{cm}^{3}$, and $4.506 \mathrm{~g} / \mathrm{cm}^{3}$ (Table $1)$, respectively [17-21].

Then, in order to assess the impact of prosthesis on dose distribution, PDD and profile curves $(\mathrm{d}=5 \mathrm{~cm})$ were calculated for women and men's prostheses with different materials at a $10^{\times} 10 \mathrm{~cm}^{2}$ filed and the results were compared in both cases, with and without prostheses.

\section{Results}

The obtained results indicated that there was a good agreement between the simulation results and those of dosimetry (the difference was about $2 \%$ for differential PDD curves (Figure 2a) and about 3.5\% for the profile (Figure 2b)).

After checking the validity of simulation, in order to assess the impact of prosthesis on radiotherapy dose distribution, men and women's prostheses with four different materials were added to the simulation program according to Table 1. PDD curves were drawn for prostheses with different materials and dimensions for women (Figure 3) and men (Figure 
Table 1: Elemental composition and mass density of four hip prostheses materials

\begin{tabular}{|c|c|c|c|c|c|c|c|}
\hline \multicolumn{2}{|c|}{$\begin{array}{l}\text { Cr-Co-Mo alloy } \\
\rho=8.20\left(\mathrm{~g} / \mathrm{cm}^{3}\right)\end{array}$} & \multicolumn{2}{|c|}{$\begin{array}{l}\text { Stainless Steel } \\
\rho=6.45\left(\mathrm{~g} / \mathrm{cm}^{3}\right)\end{array}$} & \multicolumn{2}{|c|}{$\begin{array}{c}\text { Ti alloy } \\
\rho=4.48\left(\mathrm{~g} / \mathrm{cm}^{3}\right)\end{array}$} & \multicolumn{2}{|c|}{$\begin{array}{c}\mathrm{Ti} \\
\rho=4.506\left(\mathrm{~g} / \mathrm{cm}^{3}\right)\end{array}$} \\
\hline Element & WF (\%) & Element & WF (\%) & Element & WF (\%) & Element & WF (\%) \\
\hline Co & 61.90 & $\mathrm{Fe}$ & 62.72 & $\mathrm{Ti}$ & 89.17 & $\mathrm{Ti}$ & 100 \\
\hline $\mathrm{Cr}$ & 28.00 & $\mathrm{Cr}$ & 21.00 & $\mathrm{Al}$ & 6.20 & & \\
\hline Mo & 6.00 & $\mathrm{Ni}$ & 9.00 & V & 4.00 & & \\
\hline Mn & 1.00 & $\mathrm{Mn}$ & 3.60 & $\mathrm{Fe}$ & 0.30 & & \\
\hline Si & 1.00 & Mo & 2.5 & 0 & 0.20 & & \\
\hline $\mathrm{Fe}$ & 1.00 & $\mathrm{Si}$ & 0.75 & $C$ & 0.08 & & \\
\hline $\mathrm{Ni}$ & 0.75 & $\mathrm{~N}$ & 0.43 & $\mathrm{~N}$ & 0.05 & & \\
\hline C & 0.35 & & & & & & \\
\hline
\end{tabular}

4). Furthermore, profile curves were drawn for prostheses with different materials for women (Figure 5) and men (Figure 6).

As seen in Figures (3) to (6), scattered electrons from the surface of the metal cause an increase in dose at the intersection of the tissue (tissue equivalent water phantom) and metal. Because of the short range of the scattered electrons, this increase in dose is only a few millimeters. Moreover, the beam passing through the metal and attenuation of the beam by it make a decrease only at the end of the metal. This decrease is shown in Figures (3) to (6) in the entire metal surface area.

The results summarized in Table 2 show an increase in PDD at the intersection of the tissue and prosthesis and also a decrease in dose at the end of the prosthesis used for men and women with different materials. However, there was no significant difference between the prostheses used for men and women.

Also, the obtained results indicate that the percentage of difference obtained between the PDD curves and profile is maximum for prosthesis used for men made of cobalt-chromiummolybdenum alloy with higher density.

\section{Discussion}

The present study investigated the influencing factor, which stemmed from the existence of prosthesis in field treatment affecting fluctuation and changes in knee dose, on dose distribution. Generally, comparing the distribution doses in the water phantom, in the presence of knee prosthesis, showed the following results:

1. An increase in dose on the interface between metal and tissue when the beam enters the metal due to scattered electrons.

2. A decrease in dose induced by beam attenuation in the metal due to atomic number and high absorption in the distal area of prosthesis.

Results of this research are in line with some studies that investigated radiotherapy doses disorder in the presence of hip prostheses using simulation. Paul et al. investigated the impact of hip metal prostheses, with dimensions of $2^{\times} 2^{\times} 2 \mathrm{~cm}^{3}$ and at the depth of $4 \mathrm{~cm}$ on dose distribution at the hip area in a $10^{\times} 10$ $\mathrm{cm}^{2}$ field (photon $6 \mathrm{MV}$ ), using Monte Carlo simulation. Their results showed that different materials of metal hip prosthesis affect the radiotherapy dose distribution; however, the dose difference induced by a prosthesis made of titanium is less than stainless steel [22]. Spezi et al. investigating the effect of 4 different materials for a cylindrical hip joint prosthesis with height and diameter of $15 \mathrm{~cm}$ and $3 \mathrm{~cm}$, respectively, on dose distribution with a $10^{\times} 10 \mathrm{~cm}^{2}$ field, showed that hip prosthesis made of cobalt-chromium alloy had the high- 

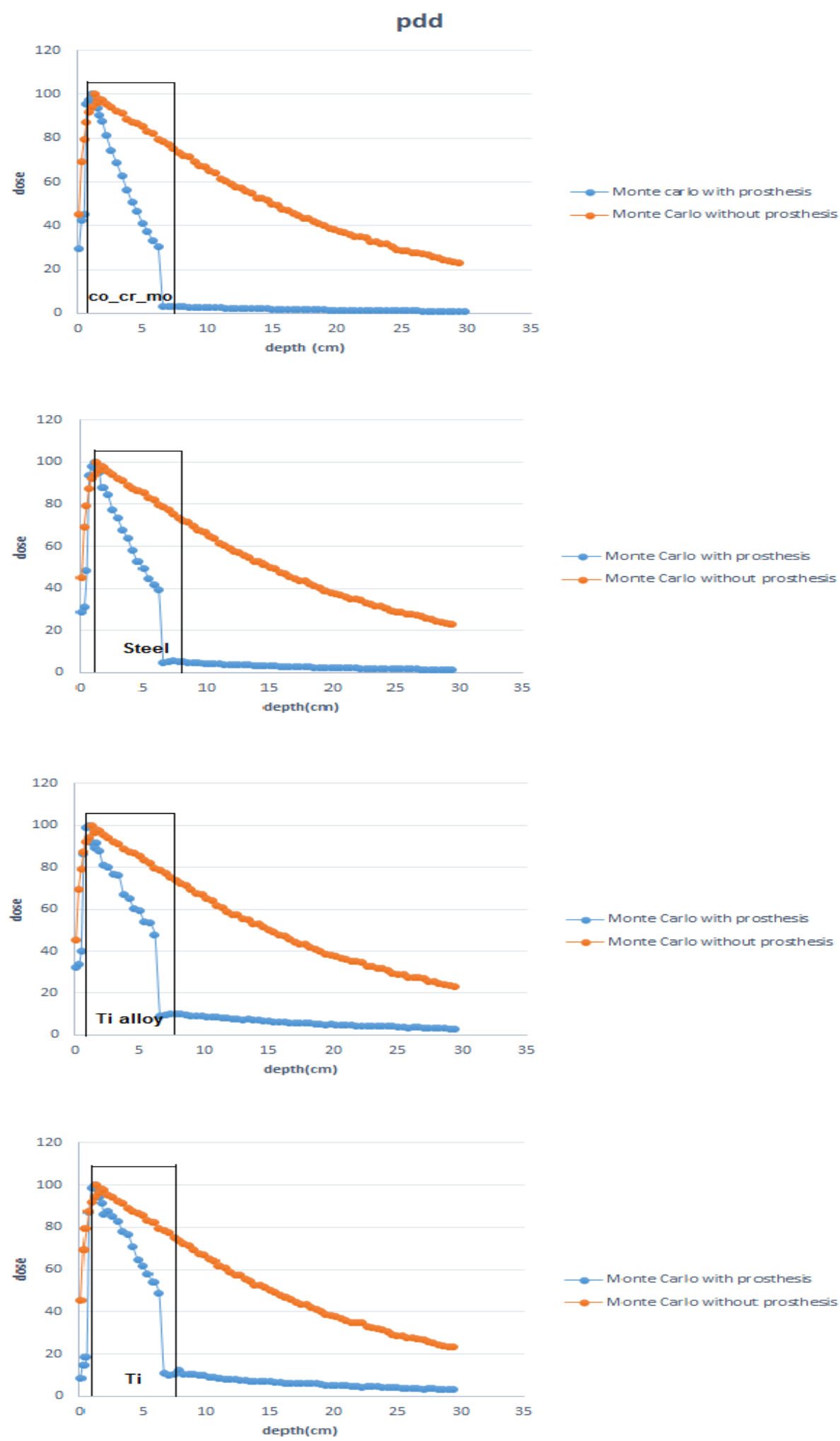

Figure 3: PDD curves calculated by MC simulation with and without women's knee prostheses made of (a) chromium - cobalt - molybdenum alloy (b), stainless steel (c) titanium alloy (d) and titanium. 

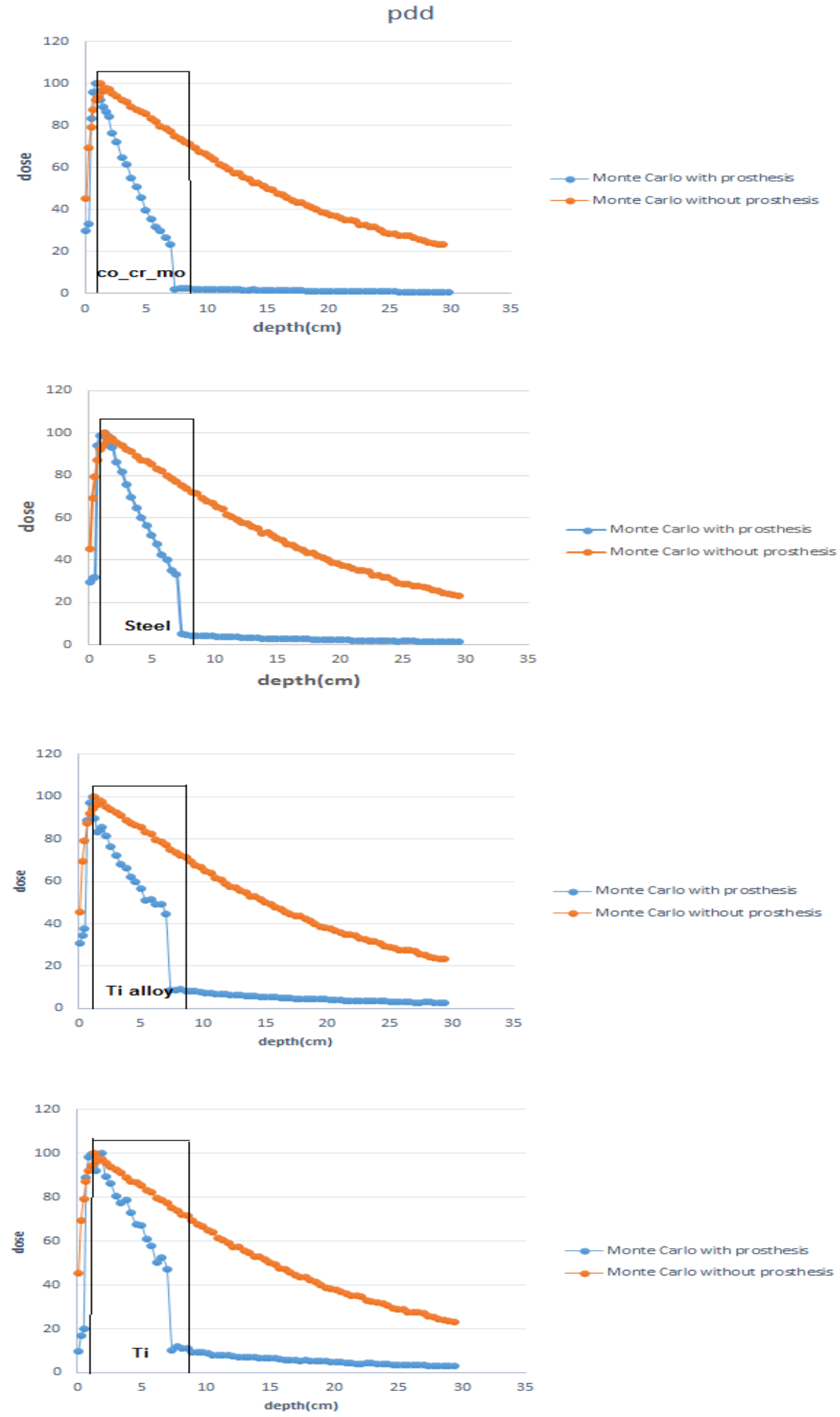

Figure 4: PDD curves calculated by MC simulation with and without men's knee prostheses made of (a) chromium - cobalt - molybdenum alloy (b), stainless steel (c) titanium alloy (d) and titanium. 

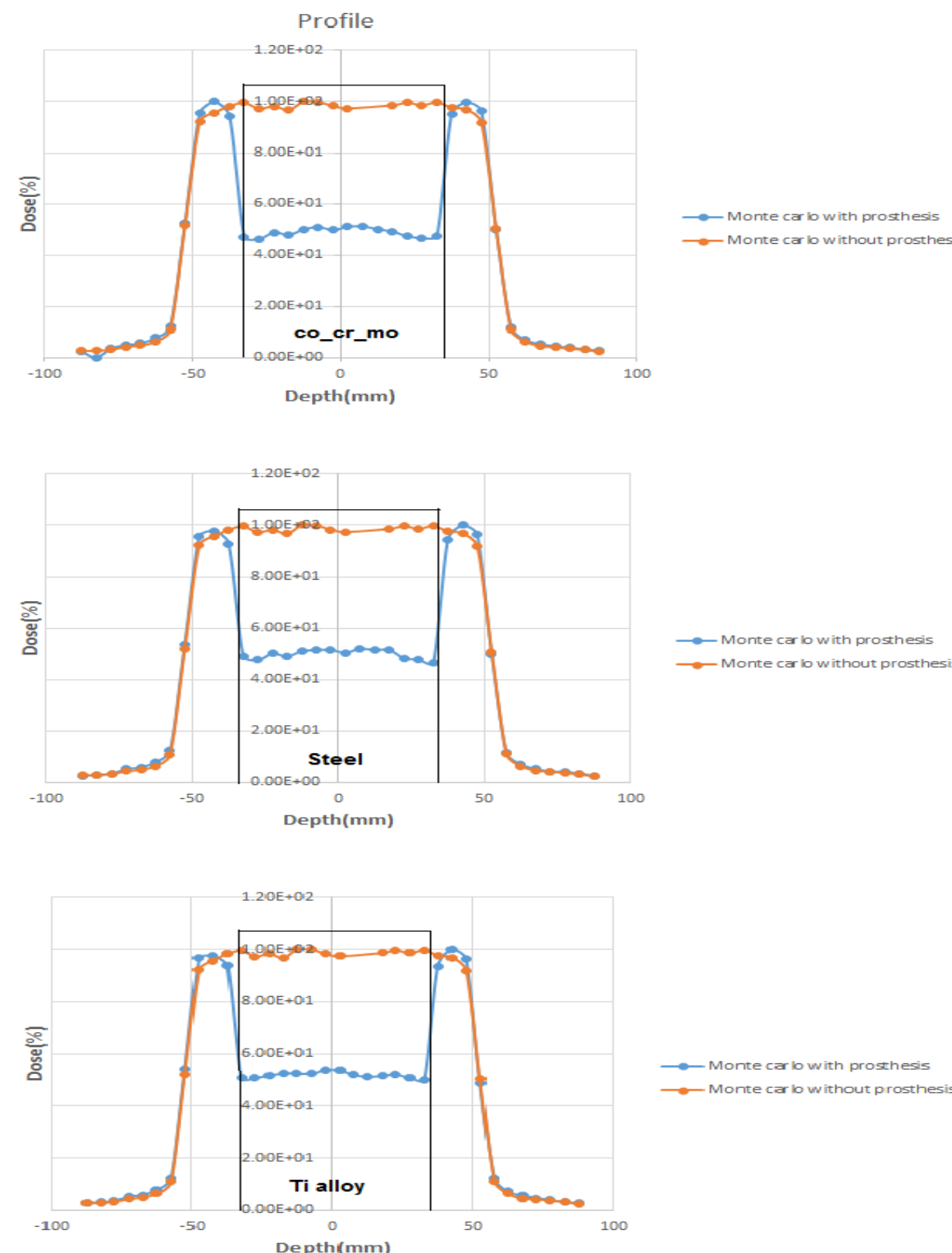

Depth(mm)

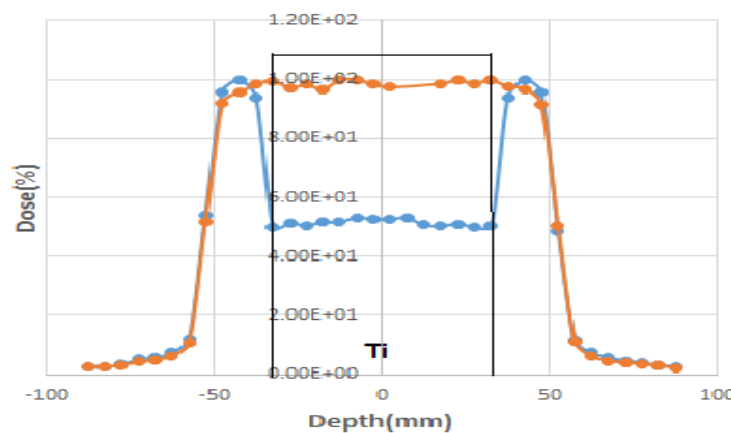

Figure 5: Dose profiles curves calculated by MC simulation with and without women's knee prostheses made of (a) chromium - cobalt - molybdenum alloy (b), stainless steel (c) titanium alloy and (d) titanium. 

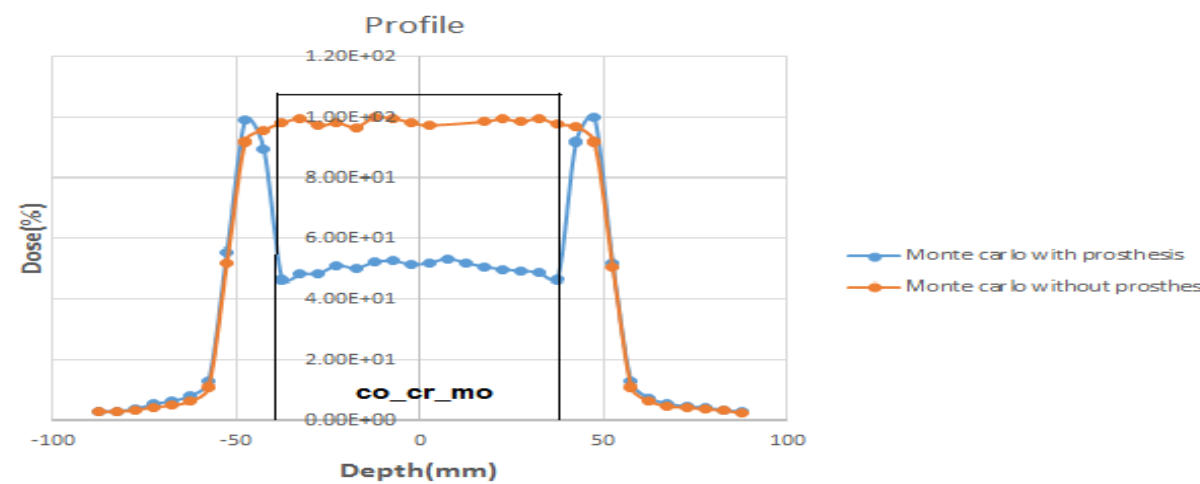

- Monte car lo without prosthesis
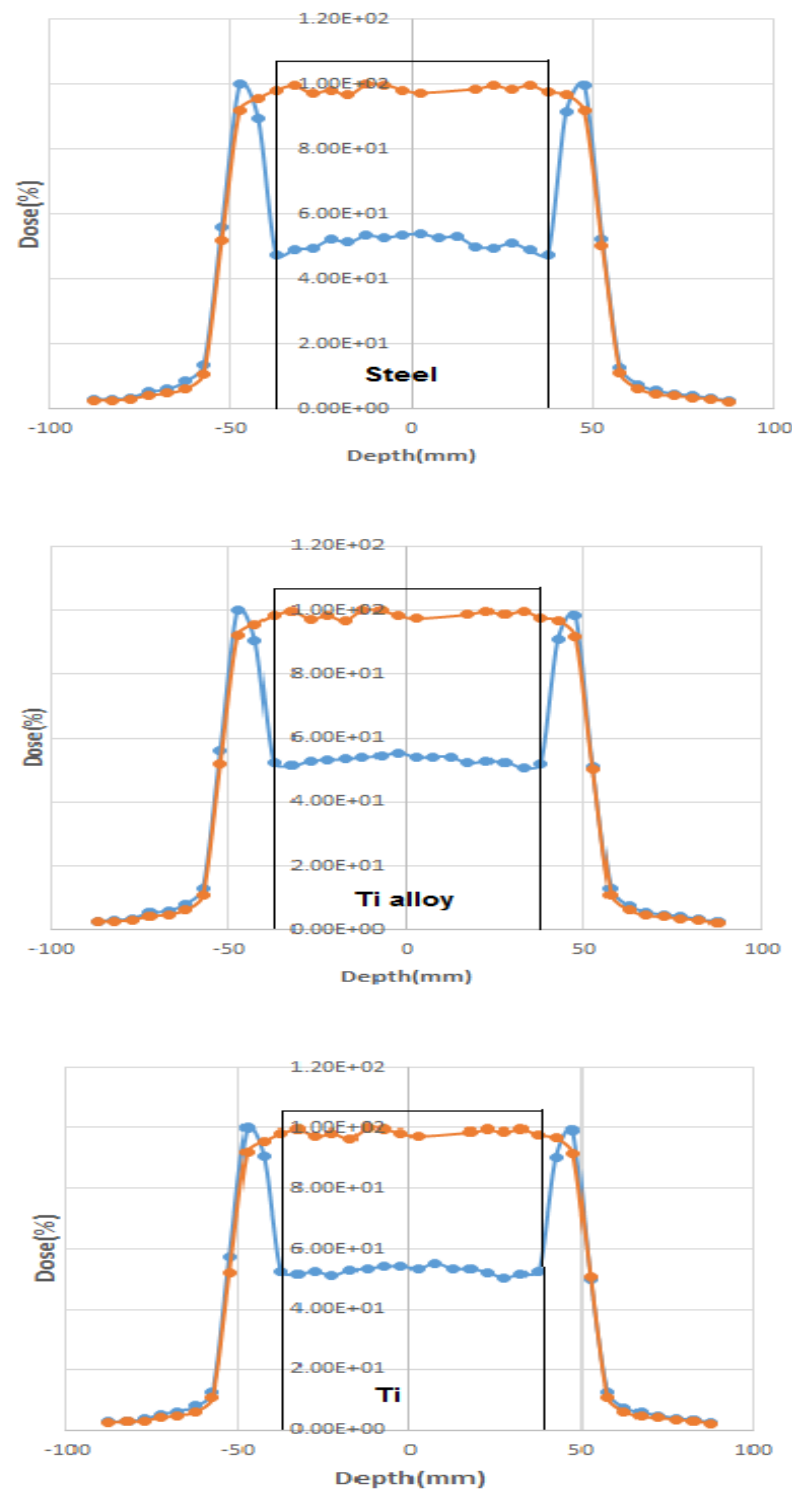

Figure 6: Dose profiles curves calculated by MC simulation with and without men's knee prostheses made of (a) chromium - cobalt - molybdenum alloy (b), stainless steel (c) titanium alloy and (d) titanium. 
Table 2: Percentage of dose increment and reduction for different men and women prosthesis.

\begin{tabular}{ccccc}
\multirow{2}{*}{ Material } & \multicolumn{2}{c}{ Percentage of dose increment (\%) } & \multicolumn{2}{c}{ Percentage of dose reduction (\%) } \\
\cline { 2 - 5 } & Men & Women & Men & Women \\
\hline Cr_Co_Mo alloy & 6.81 & 6.4 & 41.18 & 40.87 \\
\hline SST & 6.1 & 5.96 & 40.66 & 40.36 \\
\hline $\mathrm{Ti}$ alloy & 4 & 3.87 & 37.76 & 36.94 \\
\hline $\mathrm{Ti}$ & 4.29 & 3.94 & 37.51 & 36.69
\end{tabular}

est dose difference in the profile curve and titanium alloys had the lowest impact on dose distribution [23].

This study investigated the impacts of knee prosthesis on radiotherapy dose distribution. The results indicate that those areas completely blocked by the metal prosthesis experience a decrease in dose. Furthermore, the scattering effect of the beam from the metal leads to an increase in dose in knee bone and adjacent tissues. By changing the prosthesis material from high to low density, dose distribution and dose at the beginning and end of the metal decreased.

\section{Conclusion}

The metal prostheses in the radiation field leads to dose fluctuations in the tumor and normal tissue adjacent to the prosthesis. It can be assumed that changes dose depends on the material (density and atomic number) and the prosthesis cross-section. If the prosthesis cross-section and density increase, dose fluctuations in the surrounding area will ncrease which ultimately leads to a dose reduction in the tumor area and an increase in healthy tissues. Based on the results obtained, usage of titanium and titanium alloy with low density is recommended for knee joint arthroplasty. Also, more attention should be given to calculation related to the existence of prosthesis considering patients treatment time. While treatment planning of patients, undergone prosthesis implantation, it is recommended to emit the beam in such a way that the prosthesis is notin the path of radiation.

\section{Acknowledgment}

This work was supported by Arak University of Medical Sciences [Grant number: 1921].

\section{Conflict of Interest}

None

\section{References}

1. Reft C, Alecu R, Das IJ, Gerbi BJ, Keall P, Lief E, et al. Dosimetric considerations for patients with HIP prostheses undergoing pelvic irradiation. Report of the AAPM Radiation Therapy Committee Task Group 63. Med Phys. 2003;30:1162-82. doi: 10.1118/1.1565113. PubMed PMID: 12852541.

2. Friedrich RE, Todorovic M, Krull A. Simulation of scattering effects of irradiation on surroundings using the example of titanium dental implants: a Monte Carlo approach. Anticancer Res. 2010;30:1727-30. PubMed PMID: 20592369.

3. Wang R, Pillai K, Jones PK. Dosimetric measurement of scattered radiation from dental implants in simulated head and neck radiotherapy. Int J Oral Maxillofac Implants. 1998;13:197-203. PubMed PMID: 9581405.

4. Rosewall T, Kong V, Vesprini D, Catton C, Chung $\mathrm{P}$, Menard $\mathrm{C}$, et al. Prostate delineation using CT and MRI for radiotherapy patients with bilateral hip prostheses. Radiother Oncol. 2009;90:32530. doi: 10.1016/j.radonc.2008.11.015. PubMed PMID: 19121547.

5. Bazalova M, Coolens C, Cury F, Childs P, Beaulieu $L$, Verhaegen F, editors. Monte Carlo dose calculations for phantoms with hip prostheses. Journal of Physics: Conference Series; 2008: IOP Publishing. doi: 10.1088/1742-6596/102/1/012001.

6. Wieslander E, Knoos T. Dose perturbation in the presence of metallic implants: treatment planning system versus Monte Carlo simulations. Phys Med Biol. 2003;48:3295-305. doi: 10.1088/00319155/48/20/003. PubMed PMID: 14620059 . 
7. Mesbahi A, Nejad FS. Monte Carlo study on the impact of spinal fixation rods on dose distribution in photon beams. Reports of Practical Oncology \& Radiotherapy. 2007;12:261-6.doi: 10.1016/s15071367(10)60064-8.

8. Reitemeier B, Reitemeier G, Schmidt A, Schaal $W$, Blochberger P, Lehmann D, et al. Evaluation of a device for attenuation of electron release from dental restorations in a therapeutic radiation field. J Prosthet Dent. 2002;87:323-7.doi: 10.1067/ mpr.2002.122506 . PubMed PMID: 11941360.

9. Shahbazi GD, Changizi B, Jomehzadeh A, Larizadeh $\mathrm{MH}$. The effect of contrast media on treatment planning and dose calculation in radiation therapy of pelvis cancers. J Med Isfahan School. 2017;34:1389-94.

10. Chin DW, Treister N, Friedland B, Cormack RA, Tishler RB, Makrigiorgos GM, et al. Effect of dental restorations and prostheses on radiotherapy dose distribution: a Monte Carlo study. J Appl Clin Med Phys. 2009;10:2853. PubMed PMID: 19223833; PubMed Central PMCID: PMC5720502.

11. Shimozato T, Yasui K, Kawanami R, Habara K, Aoyama Y, Tabushi K, et al. Dose distribution near thin titanium plate for skull fixation irradiated by a 4-MV photon beam. Journal of Medical Physics/Association of Medical Physicists of India. 2010;35:81.doi: 10.4103/0971-6203.62199.

12. Cohen AJ, Koral KF. Backscattering and secondary-electron emission from metal targets of various thicknesses. 1965.

13. Williams MV, Burnet NG, Sherwin E, Kestelman R, Geater AR, Thomas SJ, et al. A radiotherapy technique to improve dose homogeneity around bone prostheses. Sarcoma. 2004;8:37-42. doi: 10.1080/13577140410001679248. PubMed PMID: 18521392; PubMed Central PMCID: PMC2395598.

14. Schneider U, Fiechtner A, Besserer J, Lomax A. Neutron dose from prostheses material during radiotherapy with protons and photons. Phys Med Biol. 2004;49:N119-24. doi: 10.1088/0031- 9155/49/9/n01 .PubMed PMID: 15152934.

15. Hammersley J. Monte carlo methods: Springer Science \& Business Media; 2013.

16. Seif F, Bayatiani MR. Evaluation of electron contamination in cancer treatment with megavoltage photon beams: monte carlo study. J Biomed Phys Eng. 2015;5:31-8. PubMed PMID: 25973409; PubMed Central PMCID: PMC4417618.

17. Hosseinzadeh H, Tarabichi S, Shahi A. Special Considerations in Asian Knee Arthroplasty. Chapter. 2013.

18. Insall JN, Binazzi R, Soudry M, Mestriner LA. Total knee arthroplasty. Clin Orthop Relat Res. 1985:1322. PubMed PMID: 3967412.

19. Popa D, Tarnita DN, Tarnita D, Grecu D. The generation of the three-dimensional model of the human knee joint. Rom J Morphol Embryol. 2005;46:279-81. PubMed PMID: 16688363.

20. Bahreyni Toossi MT, Behmadi M, Ghorbani M, Gholamhosseinian H. A Monte Carlo study on electron and neutron contamination caused by the presence of hip prosthesis in photon mode of a 15 MV Siemens PRIMUS linac. J App/ Clin Med Phys. 2013;14:52-67. doi: 10.1120/jacmp.v14i5.4253. PubMed PMID: 24036859; PubMed Central PMCID: PMC5714559.

21. Jou M-DTS-B, Hsieh M-S. Three-dimensional geometric constraint evaluation and analysis for determining commercial knee prosthesis. Journal of Medical and Biological Engineering. 2002;22:13945.

22. Keall PJ, Siebers JV, Jeraj R, Mohan R. Radiotherapy dose calculations in the presence of hip prostheses. Med Dosim. 2003;28:107-12. doi: 10.1016/S0958-3947(02)00245-5. PubMed PMID: 12804709.

23. Spezi E, Palleri F, Angelini A, Ferri A, Baruffaldi $F$, editors. Characterization of materials for prosthetic implants using the BEAMnrc Monte Carlo code. Journal of Physics: Conference Series; 2007;74:021016. doi: 10.1088/17426596/74/1/021016. 